DOI 10.37882/2223-2982.2021.07.44

\title{
ИМПЛИЦИТНОСТЬ СЕМАНТИЧЕСКОГО СУБЪЕКТА В РЕЗУЛЬТАТИВНЫХ КОНСТРУКЦИЯХ (НА МАТЕРИАЛЕ ФРАНЦУЗСКОГО И РУССКОГО ЯЗЫКОВ) ${ }^{1}$
}

\section{IMPLICITNESS OF THE SEMANTIC SUBJECT IN EFFECTIVE CONSTRUCTIONS (BASED ON THE MATERIAL OF THE FRENCH AND RUSSIAN LANGUAGES)}

\section{A. Chervony}

Summary: The article deals with the implicit expression of the semantic subject. In the article that is based on the material of the French and Russian languages, the resultatives are considered as syntactic means of the formal implicitness of a real subject. The semantic subject is implicit due to the fact that it is communicatively, and, consequently, lexically redundant in the structure of the resultative. The marker of the semantic subject in the resultative constructions is the meaning of the past participle, and the subject is specified within the context and communicative situation.

Keywords: the semantic subject, implicitness, a syntactic construction, resultative, transformation.

\author{
Червоный Александр Михайлович \\ Д. филол.н., дочент, Таганрогский институт им. \\ А.П. Чехова (филиал) ФГБОУ ВПО «РГЭУ (РИНХ)» \\ ckutrik@yandex.ru
}

Аннотация: Статья посвящена имплицитному выражению семантического субъекта. В работе на материале французского и русского языков рассматриваются результативы как синтаксические средства формальной невыраженности реального деятеля. Причина имплициности семантического субъекта объясняется его коммуникативной, а, следовательно, и лексической избыточностью в структуре результатива. Маркером семантического субъекта в конструкциях - результативах является значение причастия прошедшего времени, а его конкретизация осуществляется в рамках контекста и коммуникативной ситуации.

Ключевые слова: семантический субъект, имплициность, синтаксическая конструкция, результатив, трансформация.

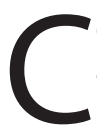

емантический субъект, под которым мы понимаем активную, разумную, обладающую способностью к речи, субстанцию, каузирующую некое действие и выполняющую его физически или ментально - человека.

В языке семантический субъект получает самое разное выражение: от $Я$ говорящего/думающего/чувствующего/действующего до полного его формального устранения - редукции из структуры предложения/высказывания [5].

К синтаксическим конструкциям, имплицитно выражающим субъект, с полным правом можно отнести результативы, которые представляют собой разновидность пассивных конструкций.

Как известно, результативы выражают некое новое состояние предмета/ объекта или человека, возникшее в результате совершения определенного преднамеренного или непреднамеренного действия.

Важно отметить: восприятие реципиента обращено на качественно иное состояние субстанции, которое проявляется в дифференциации состояния №1 с возникшим состоянием №2 несмотря на то, что состояние №2 могло образоваться значительно раннее момента его осознания и номинации субъектом. Следовательно, осуществление того или иного качественного преобразования могло произойти в результате действий, предполагающих активное природное или антропоморфное начало, вызвавшее трансформации.

Денотатом внеязыковой ситуации результатива является ситуация, состоящая из двух совмещенных во времени и пространстве моментов, вбирающих в себя действие и результат, возникший вследствие этого действия.

Исследование выполнено при финансовой поддержке Российского фонда фундаментальных исследований (РФФИ) в рамках научного проекта № 19-012-00062 «Полифония семантического субъекта (на материале русского, французского, английского и немецкого языков)», проводимого в ФГБОУ ВО «РГЭУ (РИНХ)»; руководитель - доктор филол. наук, доцент, заведующий кафедрой немецкого и французского языков А.М. Червоный 
(Рус.) Субъект - Действие (Время) $\rightarrow$ Объект (Состояние) №1 $\rightarrow$ Объект (Состояние) №2.

(Фр.) Sujet - Action (Temps) $\rightarrow$ Objet (Son etat) №1 $\rightarrow$ Objet (Son etat) №2.

Таким образом, умозаключение и констатация в речи нового качества той или иной субстанции предполагает знание положения вещей, предшествующих новой реальности.

Синтаксические конструкции - результативы присутствуют в номенклатуре синтаксических конструктов многих языков, в том числе в русском и во французском языках.

Например: 1) Я вымыл посуду $\rightarrow$ посуда вымыта;

2) Он выполнил это задание $\rightarrow$ задание выполнено;

3) J'avais chargé le revolver $\rightarrow$ le revolver était chargé;

4) On eut posé une assiette $\rightarrow$ une assiette fut posée.

В приведенных примерах-результативах эксплицируется результат действия, имплицируется семантический субъект.

Следует отметить: результативы русского и французского языков симметричны в плане семантики и при линеаризации предложения структурно соответствуют грамматическому строю, свойственному каждому из рассматриваемых языков. В подтверждение выше сказанному в работе использовались примеры русских и французских результативов.

В процессе преобразования активной формы конструкции в пассивную и наоборот не меняются ни единицы референтного уровня, ни их соотношения с единицами семантического уровня. Меняется только соотношение единиц референтного и синтаксического уровней, т.е. единицы семантического уровня и актанты - единицы синтаксического уровня соотносятся друг с другом не непосредственно, а опосредованно, через единицы референтного уровня [4, с. 11].

Как известно, результативы характеризуются выражением законченности действий, совершенных как естественным способом, так и преднамеренно семантическим субъектом. Однако анализ отдельно взятого предложения не всегда дает однозначный ответ на вопрос о реальном производителе действия. Рассмотрим следующее предложение: Огонь на опушке потух.

Данное предложение описывает ситуацию, предполагающую либо деятеля, т.е. некто развел огонь, либо какое-либо явление, которое способствовало возгоранию. Огонь, который потенциально имеет свой внутренний природный предел, мог затухнуть сам по себе, без вме- шательства семантического субъекта, в то же время он мог быть потушен кем-либо специально, с определенной целью. Смысл этого предложения свидетельствует о самопроизвольном затухании, логический конец процесса горения наступил естественным образом, возникшее состояние не является результатом деятельности субъекта. Семантический субъект в данном случае не представлен, поскольку он не является производителем действия, перед нами описано состояние среды.

Дифференцировать естественно-природное явление от антропоморфного производителя действия позволяет значение причастия прошедшего времени - одного из наиболее семантически значимого компонента результатива.

Причастие как признак предмета по действию, образовано от прямопереходных глаголов, которые, согласно Э. Бенвениста, выражают жизненные проявления сущностей. Именно глагольная семантика способна выделить действия, присущие семантическому субъекту: сказать, написать, планировать, конструировать, cmpoumb, фабриковать, сuить, dire, écrire, construire, batir, fabriquer,coudre u m.d.

Проанализируем другой пример: Tenez, une fois, ce tiroir a été ouvert.

Знания и жизненный опыт подсказывают: выдвижной ящик обычно сам не открывается. Перед нами результат действия реального субъекта. Конструкцией ce tiroir a été ouvert отмечается один из признаков функционирования ящика - выдвигаться, но не самостоятельно, а благодаря усилиям субъекта. Тип действия указывает на одушевленного разумного деятеля.

Таким образом, на реальное присутствие семантического субъекта указывает состояние объекта воздействия.

Важную роль в детерминации семантического субъекта оказывает содержание контекста и ситуация. Результатив может стать как бы логическим выводом из соответствующей группы предложений, объединенных единым смыслом.

Например: Maillât repassa dans la salle à manger ... II s'assit sur l'unique fauteuil près de la fenêtre, alluma une cigarette, trouva à portée de sa main un cendrier ... Le cendrier était en cuivre. Il brillait comme de l'or. Jeanne (ceмантический субъект найден) avait dû l'astiquer le matin même, plus soigneusement peut-être que tout le reste [7, c. 118-119].

Говорящий знал первичное состояние дома, что позволило ему сравнить состояние комнаты до своего ухо- 
да и спустя некоторое время, вернувшись, т.е. состояние №2 характеризуются определенным временным интервалом. Действие Жанны имело место в прошлом и предшествовало возвращению Майя, что соответственным образом отражено временными формами глаголов.

Результат действия может быть отражен в пространстве и времени.

Например: Puis, se saisissant à nouveau de la clé, il entreprit de dévisser les écrous de bronze. En quelques instants ils étaient alignés par terre [8, c. 81].

Следует отметить, что действие, направленное на объект, достигнув определенного результата, прекращается, от семантического субъекта больше не требуется усилий. Прекращение воздействия на объект знаменует период временного покоя и вследствие этого перехода результатива в категорию статива.

Например: Только початая бутылка водки выдает, что квартира не женская. Посуда вся перетерта до зеркального блеска, по линеечке стоит и лежит. Было сложно не нарушить этого стройного порядка, чтобы не выдать, что мы там были [2, с. 227]. Семантический субъект не назван, поскольку он говорящему известен.

Разграничение концепта «результат» от концепта «состояние» связано, на наш взгляд, с умственной способностью воспринимающего, исходя из конкретной ситуации и благодаря контексту, делать заключения о действительном намерении говорящего выделить ли результат действия или состояния объекта, а может то и другое вместе и сразу [1, с. 81].

Различие между стативом и результативом состоит в том, что статив сообщает только о состоянии предмета, результатив же - одновременно о состоянии и предшествующем ему действии, результатом которого явилось это состояние [3, с. 7].

Проанализируем французские конструкции, которые подводят итог действию субъекта, фиксируют результат его акциональности.

Например: 1) En partie, certains mannequins sont préparés dans nos ateliers, mais en général nous nous tenons au courant de tout ce qu'il y a de moderne. Манекены подготовлены к новому сезону.

2) Le régiment venait du Nord où il avait été formé après un circuit de fous....[6, c. 24]. Полк формируется один раз, такова традиция.

Следует отметить, что темпоральный отрезок состояния объекта величина непостоянная. Относительно константное, более-менее длительное состояние, может сохраняться довольно долго, хотя и оно изменяется, т.к. в природе ничего неизменного нет, но изменения вызваны скорее течением времени, чем активным вмешательством реального деятеля. Однако не исключено и воздействие субъекта на объект.

Воздействие на объект может быть направлено на сохранение качества объекта, на незначительные в нем изменения, на кардинальное.

Длительность состояния определяется разумной деятельностью семантического субъекта, который иногда старается его сократить или продлить. В этом проявляется интенциальный подход реального деятеля к объекту воздействия.

Таким образом, предложения со значением результатива соединяют как бы различные моменты описываемой ситуации, заключают ее, подводят итог, резюмируют.

Синтаксическими структурами Ninan + être + P.p. описывается следствие, наступившее после соответствующей деятельности семантического субъекта.

Как показал анализ фактического материала, в языке реальный деятель довольно часто не получает своего формального выражения в пассивных результативах, семантический субъект оказывается коммуникативно избыточным в структуре предложения/ высказывания.

Двучленный грамматический пассив с выступающим на первый план результатом глагольного действия и его объектом с вытесненным реальным производителем действия предстает как совершенно особое специфическое средство в логике языка, качественно и количественно преобразующее структуру фразы.

Данной синтаксической конструкцией искусственно концентрируется внимание на конечной точке динамической ситуации.

Подобные двучленные структуры фиксируют результат действия как бы в отрыве от реального деятеля. В конструкциях-результативах семантический субъект выражается косвенным образом, для обнаружения которого иногда приходится выйти за границы отдельно взятого, изолированного предложения.

Причины употребления пассивных, а не активных конструкций кроются в отсутствии возможности или необходимости информировать воспринимающего о референтах семантического субъекта, а также в стремлении сосредоточить внимание коммуниканта на референтах объекта и на действии, которому они подвергались, и которое, обычно, имеет наблюдаемые результаты. 


\section{ЛИТЕРАТУРА}

1. Гак В.Г. Неопределенноличность в плане содержания и в плане выражения. //Теория функциональной грамматики. СПб.: Наука, 1991. - С. 72 - 86.

2. Миронов В. Н. Крпич из Лондона.- М.: Эксмо, 2021. - 320 с.

3. Недялков В.П., Яхонтов С.Е. Типология результативных конструкций (результатив, статив, пассив, перфект). Л.: Наука, 1983. - С. 5- 41.

4. Храковский В.С. Диатеза и референтность. //Залоговые конструкции в разноструктурных языках. Л.: Наука, 1981. - с. 5-42.

5. Червоный А.М. Семантический субъект и имплицитность // Современная наука: актуальные проблемы теории и практики. Серия: Гуманитарные науки. 2020. №6-2. C. 168-170.

6. Lanoux A. Le commandant Watrin. M.: Ed. En langues étrangères, 1962. - 384 p.

7. Merle R. Week-end à Zuydcoote. Л. Просвещение, 1972. - 176 c.

8. Rheims M. Permis d'exhumer // Серебряный конь: Новеллы современных французских писателей / Сост. Э.М. Береговская. - М.: Просвещение, 1984. C. 73-84.

(с) Червоный Александр Михайлович (ckutrik@yandex.ru).

Журнал «Современная наука: актуальные проблемы теории и практики»

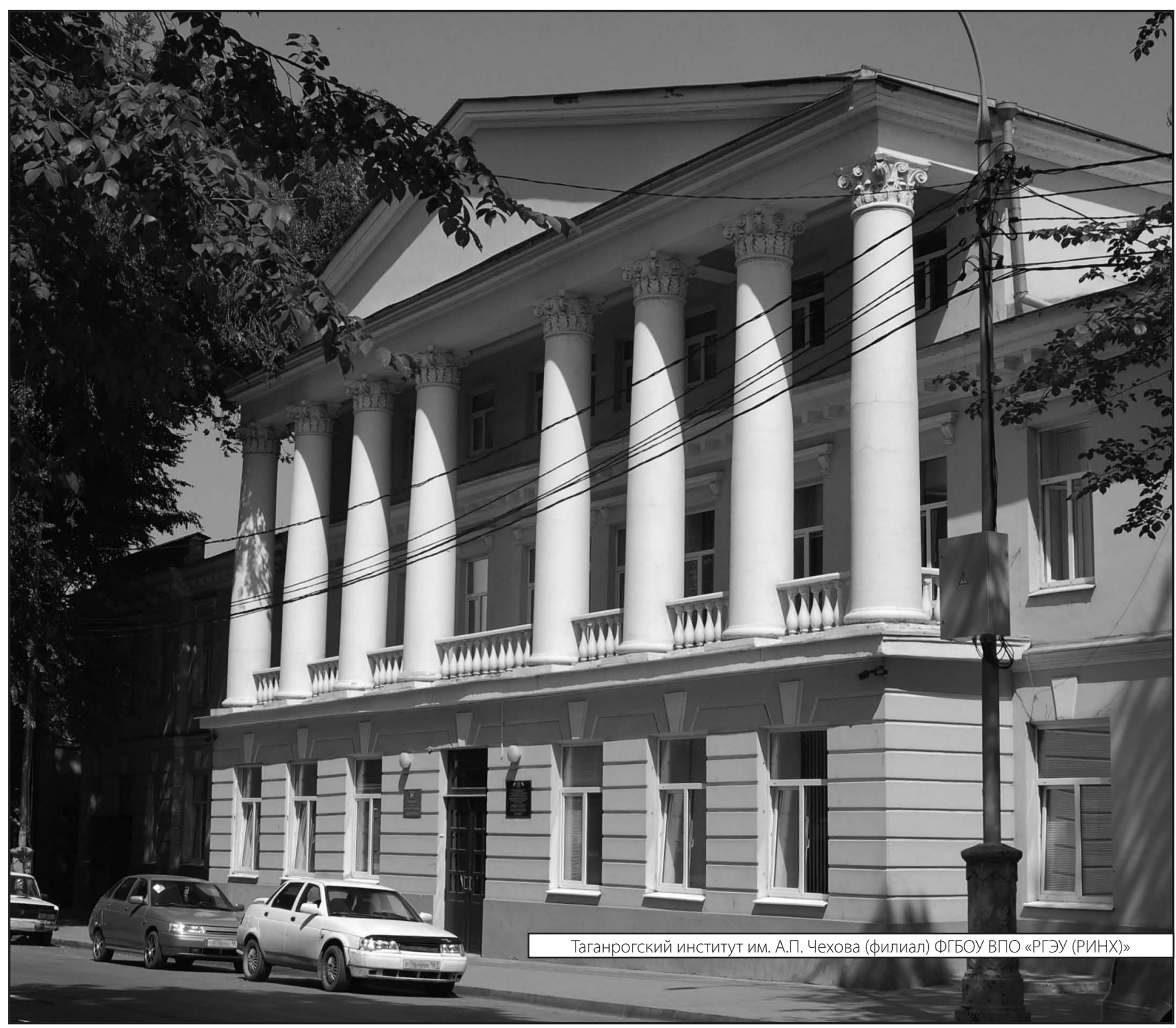

